\title{
Fracture development and fractal characteristics of overburden rock under repeated mining
}

\author{
Zhixiang Zhang $^{1,2} \cdot$ Yongbo Zhang $^{1} \cdot$ Yongxin $\mathrm{Xu}^{1,2} \cdot$ Qiang Zheng $^{1} \cdot$ Zhaoliang Wang $^{1,2} \cdot$ Liangliang Guo $^{1}$
}

Received: 3 December 2018 / Accepted: 13 January 2021 / Published online: 2 February 2021

(C) Saudi Society for Geosciences 2021

\begin{abstract}
The purpose of this paper is to provide scientific basis for the stability evaluation of overburden rock of repeated mining goaf under the expressway. The objectives of the present study are to reveal the development of overburden rock fractures under repeated mining and to identify the fractal characteristics of the overburden rock fractures. The results show that (1) the separation fracture and vertical fracture fissure are developed in the overburden rock under repeated mining; (2) after the mining of the lower coal seam, the fractures developed in the overburden rock of the goaf are obviously retained in general. The number of fractures on both sides of the goaf is relatively large, while in the central part, it is relatively small and the fractures in most areas are basically closed; (3) under the same advancing length of working face in the lower coal seam, the fractal dimension in the caving zone is larger than that of the fractured zone; (4) with the increase of the advancing length of working face in the lower coal seam, the variation trend of the fractal dimension appears from small to large and then to small and stable; (5) when the repeated mining is over and the overburden rock movement is basically stable, the ratio of the fractal dimension in the caving zone and the fractured zone is 1.067:1. The results have an important reference value for ensuring the safety of the expressways above the repeated mining goaf in Shanxi region and similar areas.
\end{abstract}

Keywords Caving zone $\cdot$ Fractured zone $\cdot$ Advancing length $\cdot$ Variation trend $\cdot$ Fractal dimension $\cdot$ Goaf

\section{Introduction}

Responsible Editor: Longjun Dong

Zhixiang Zhang

zhangzhixiang@tyut.edu.cn

$\triangle$ Yongbo Zhang

zfstzhang@sina.com

Yongxin $\mathrm{Xu}$

xuyongxin@tyut.edu.cn

Qiang Zheng

tyutzhengqiang@163.com

Zhaoliang Wang

wzliang0501@126.com

Liangliang Guo

guoliangliang@tyut.edu.cn

1 College of Water Resources Science and Engineering, Taiyuan University of Technology, Taiyuan 030024, China

2 Department of Earth Sciences, University of the Western Cape, Bellville 7535, South Africa
Shanxi region is one of the major coal energy bases in China. After years of coal mining, large-scale goafs have been formed. This has become a constraint factor for expressways and other major infrastructure projects. Due to the scarcity of available land resources, and to improve the land utilization and shorten the road mileage, the development requirements of traffic roads are more stringent due to comprehensive consideration of overall route alignment, special geological and topographic conditions. With the accelerated implementation of traffic construction projects in Shanxi region, many expressways will inevitably pass through the goafs. In the original sedimentary environment, although the coal rock masses have primary fractures, they are in the equilibrium state of the original rocks without the influence of mining. During mining, the coal rock masses bend and move under the action of redistributed tectonic stress and gravity stress. With the continuous advance of working face, the overburden rock within the pressure relief zone will undergo different degrees of deformation, rupture, and even fracture (Zhou and Lin 1999). The primary fractures are superimposed with the newly 
generated mining fractures and penetrate to form a mining fracture network (Zhang et al. 2013). During the construction of expressway, it is possible to make the overburden rock of the previously relatively stable goaf re-deformation and instability. Therefore, it is of great significance to study the characteristics of overburden rock fractures of the goafs from the perspective of safety.

For more than 30 years, scholars at home and abroad have carried out a lot of researches on the formation process and characteristics of mining fractures by using theoretical analysis, similar material simulation, numerical simulation, etc., and obtained some valuable results. For example, Sofianos (1996) studied the movements and behaviors of roof strata in longwall coal mining operations. Lu and Wang (2015) carried out a study on fracture evolution induced by coal mining using numerical method. Cheng et al. (2018) described the distribution of fractures in mining rock masses by similar material simulation experiment. Zhang et al. (2015a, b), Zhang (2017), and Wang et al. (2019) studied the deformation, movement, and fracture distribution of overlying strata using numerical methods. Zhang et al. (2018a) investigated the development of water-conducting fracture zone under the influence of coal mining. Poulsen et al. (2018) presented a numerical method that is demonstrated to be capable of representing longwall mining-induced fracturing in sedimentary rock masses. Zhang et al. (2018b) studied the fracturing characteristics of rock mass of coal mining under the condition of deep mining. Xu et al. (2018) analyzed the fracture development rule of overlying strata during coal mining under water body by using similar simulation physical test. Wang and Wang (2018) used lab experiment and numerical simulation method to describe the development characteristics of top-coal fractures under the driving forces. Zhu (2019) studied the development law of overburden mining fractures under thick loose layer and thin bedrock by using numerical simulation and field measurement. The above researches have played an important guiding role in the safe mining of coal and coalbed methane.

The distribution of mining fracture network of coal rock mass is complex and disorderly. It has both the primary fractures formed by geological structure and the mining fractures formed by coal mining, which has the characteristics of structural and uncertainty, so it is difficult to describe by using conventional theories. Mandelbrot (1983) founded the fractal geometry and used fractal dimension to describe the irregular and disordered phenomena and behaviors in nature, which provides another effective way to describe the complex and disordered mining fracture networks. The studies (Babadagli 2001; Zhang and Liu 2004) show that the distribution from a single mining fracture to a fracture network of rock mass has fractal characteristics. In the past 20 years, scholars have tried to use fractal theory to describe the evolution of rock mass fracture network in coal mining, and have made some progress. For instance, Wang et al. (2012) studied the fractal characteristics of mining fracture networks by using RFPA software. Li et al. (2015) concluded that the fractal dimension is controlled by factors such as the length, width, number, and distribution of the fracture. Li et al. (2014) and Song et al. (2017) described the spatiotemporal evolution law of mining fractures using fractal theory. Zhang et al. (2015a, b) investigated the fractal characteristics of 3D mining-induced fractures using triaxial tests. Liang et al. (2019) analyzed the fractal evolution law of mining fractures by using water-rock similar material simulation experiments. Fan et al. (2019) used fractal dimensions to describe the development process and system evolution of mining fractures. In addition, Feng et al. (2017) researched the fractal characteristics of mining fractures of steep coal seam. Thus, scholars have revealed the scientific nature of using fracture theory to study fracture networks. However, due to the different geological conditions and the mechanical properties of the rock mass, the pertinence of the research content and the limitations of the conclusions are brought about. It is worth noting that these studies are all aimed at the single coal seam mining. Although Li et al. (2016) and Wang et al. (2017) conducted experimental studies on the morphology and evolution law of overburden rock fractures under repeated mining, the research on fractal dimension of overburden rock fractures under repeated mining is still relatively rare, and further research is needed.

Many of the proposed expressways in Shanxi region will pass through the goafs of coal mines. The overburden rock fractures have developed in these goafs, and will endanger the safety of the proposed expressways. The development and distribution of overburden rock fractures under repeated mining are more complex than that of single coal seam, and the fracture network affects whether the overlying rock mass collapses to a certain extent. At present, most researchers ignore or do not focus on the impact of overburden rock fractures under repeated mining. Therefore, it is very necessary to carry out research on the fracture development and fractal characteristics of overburden rock under repeated mining. The proposed Lishi-Jundu Expressway is located in Shanxi region, with a total length of $38.542 \mathrm{~km}$, passing through the goaf of Tongde coal mine. The purpose of this paper is to provide scientific basis for the stability evaluation of overburden rock of repeated mining goaf under the expressway. Taking the goaf of Tongde coal mine under the Lishi-Jundu Expressway as a geological prototype, the physical similar material simulation experiment is used to simulate the development and distribution of overburden rock fractures under repeated mining, and the fractal geometry theory is used to study the fractal characteristics of overburden rock fractures in the caving zone and the fractured zone of repeated mining goaf. The results can provide the necessary theoretical basis for the relevant personnel to scientifically and rationally carry out the design of foundation 
treatment of repeated mining goaf under the expressways in Shanxi region and similar areas.

\section{Materials and methodology}

\section{Physical similar material simulation experiment}

In this laboratory physical similar material simulation experiment, the geological and mining conditions of the goaf of Tongde coal mine under the Lishi-Jundu Expressway are taken as the prototype, and the route from LK19+195 to LK19+ 495, $300 \mathrm{~m}$ long, is taken to simulate the repeated mining of coal seams, i.e., mining the upper 4\# coal seam and the lower $5 \#$ coal seam. The model is designed to simulate the horizontal coal seams. The experiment is carried out on a plane stress model test rig to simulate the development of rock mass fractures under repeated mining. The size of the laboratory physical model frame is $3 \mathrm{~m} \times 0.3 \mathrm{~m} \times 1.82 \mathrm{~m}$ (length $\times$ width $\times$ height), as shown in Fig. 1. The mining method of the model coal seams is called the Strike Longwall Fully Caving Mining, with the mining width of the upper and lower coal seam being $2.40 \mathrm{~m}$.

Based on the similar simulation theory, the geometric similarity, bulk density similarity, stress similarity, and time similarity of each physical quantity should be met in the physical experiment. After comprehensively considering the above factors, the model parameters are designed as follows:

(1) Considering the actual geological conditions of the mining area, the geometric similarity constant was selected to be $\alpha_{1}=100$.

(2) The weighted average bulk density $\gamma_{\mathrm{p}}$ of the prototype rock formation is calculated to be $23.1 \mathrm{kN} / \mathrm{m}^{3}$, and the bulk density $\gamma_{\mathrm{m}}$ of similar material in the model is 15.4
$\mathrm{kN} / \mathrm{m}^{3}$. Therefore, the bulk density similarity coefficient is calculated as $\alpha_{\gamma}=\gamma_{\mathrm{p}} / \gamma_{\mathrm{m}}=23.1 / 15.4=1.5$.

(3) The stress similarity constant $\alpha_{\sigma}$ is calculated to be $\alpha_{\sigma}=$ $\alpha_{1} \times \alpha_{\gamma}=100 \times 1.5=150$.

(4) Using the kinematic similarity criterion of the model under the action of gravity, the time similarity constant is defined as $\alpha_{\mathrm{t}}=(100)^{1 / 2}=10$.

Thus, the model parameters selected by the physical similar material simulation experiment are shown in Table 1.

According to the mechanical properties of the prototype loess, the similar materials used in the simulation experiment are the quartz sand as aggregate material, and the talcum powder as the cementing material. On the basis of the mechanical properties of the prototype rock, the similar materials used in the simulation experiment are the quartz sand and river sand as aggregate materials, the lime and gypsum as cementing materials, the borax as retarder, and the mica used to simulate the original layering of rock. In order to determine the physical and mechanical properties of similar materials in this experiment, test pieces are made to determine the properties. The test pieces are produced according to different ratio requirements, and the materials of various components are taken separately, add water that is $1 / 10$ of the similar material weight, and after being uniformly stirred, the mold is loaded. For a cylindrical specimen with a test block size of $0.05 \mathrm{~m} \times 0.05 \mathrm{~m}$, its heightdiameter ratio is $1: 1$. After the test piece is completed, it is dried for 7 days to ensure that the test strength is reached. The shear strength of the loess test pieces is tested. The compressive strength and tensile strength of the rock test pieces are tested. It should be pointed out that for the test pieces representing each rock formation, five groups of ratios are made. For each group of loess and rock, 3 test pieces and 6 test pieces are made, respectively. For each type of test, three groups of tests are performed, and then the average value is
Fig. 1 Similar material model device

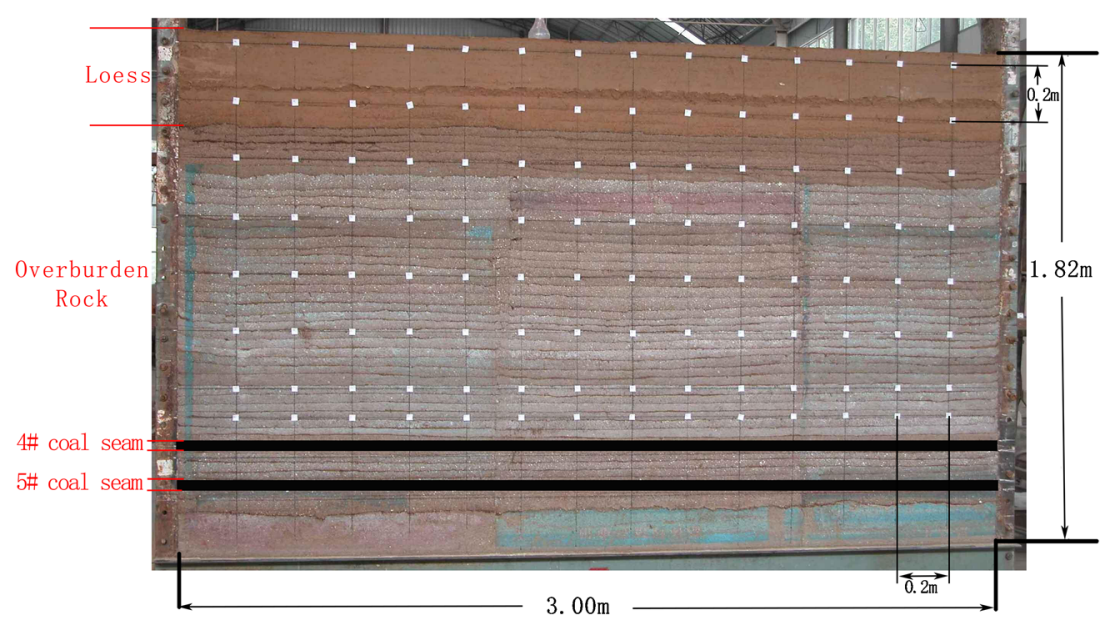


Table 1 Similarity coefficients of the experimental model

\begin{tabular}{llll}
\hline $\begin{array}{l}\text { Geometric similarity } \\
\text { coefficient } \alpha_{1}\end{array}$ & $\begin{array}{l}\text { Bulk density similarity } \\
\text { coefficient } \alpha_{\gamma}\end{array}$ & $\begin{array}{l}\text { Stress similarity } \\
\text { coefficient } \alpha_{\sigma}\end{array}$ & $\begin{array}{l}\text { Time similarity } \\
\text { coefficient } \alpha_{t}\end{array}$ \\
\hline 100 & 1.5 & 150 & 10 \\
\hline
\end{tabular}

taken. Values whose deviation is greater than $20 \%$ of the average shall be discarded, and additional test pieces shall be added for re-measurement. The chosen ratio of the loess test piece should be the cohesive force and the internal friction angle close to the prototype. The chosen ratio of the rock test piece should meet the requirements of the compression strength and tensile strength close to the designed model material. The best ratios of the similar materials of the model determined by similarity relationship are shown in Table 2. It should be noted that the loess ratio number 1601 in Table 2 means that the ratio of quartz sand to talcum powder is $160: 1$. The first number in the rock ratio number in Table 2 represents the ratio of sand to cement, and the second and third numbers represent the ratio of lime to gypsum in the cement.

When installing the model, pour the uniformly stirred material into the model, and then compact it with a compaction hammer. The height should conform to the height of each model layer, so that the similar materials adhere to the established bulk density similarity ratio. Spread a layer of mica powder between the layers to simulate the bedding, and the production of each layer should be completed within $20 \mathrm{~min}$. After the experimental model is installed, $50 \mathrm{~g}$ of material is dug and placed in a thermostat for humidity test every day. When the humidity is reduced to less than $2 \%$, the coal mining work can be started.

On the basis of the time similarity ratio, the mining speed of the model is $0.04 \mathrm{~m} / \mathrm{h}$, leading to a simulated mining time of 2.5 days. The physical experiment is firstly mining the upper seam (4\# coal seam), after the upper seam is mined out, and then immediately mining the lower seam (5\# coal seam) until it is mined out. In the specific experiment, firstly observe the development and distribution of overburden rock fractures under repeated mining, and then count the number of overburden rock fractures under repeated mining at different advancing lengths of the lower seam.

\section{Calculation of fractal dimension of overburden rock fractures under repeated mining}

The distribution of fractures in mining overburden rock has self-similarity and fractal characteristics (Song et al. 2017; Liang et al. 2019; Fan et al. 2019). Therefore, for the fracture distribution of mining overburden rock under various conditions, the fractal dimension of fractures of mining overburden rock can be obtained by changing the degree of rough visualization. According to the fractal geometry theory (Mandelbrot 1983), this experiment uses the covering method (grid

Table 2 Mechanical index of prototype and similar material ratio of the experimental model

\begin{tabular}{|c|c|c|c|c|c|c|}
\hline Number & $\begin{array}{l}\text { Lithology (from top down } \\
\text { sequence) }\end{array}$ & $\begin{array}{l}\text { Thickness } \\
(\mathrm{m})\end{array}$ & $\begin{array}{l}\text { Natural bulk density }(\mathrm{kN} / \\
\left.\mathrm{m}^{3}\right)\end{array}$ & $\begin{array}{l}\text { Compression strength } \mathrm{Rc} \\
\text { (MPa) }\end{array}$ & $\begin{array}{l}\text { Tensile strength Rp } \\
(\mathrm{MPa})\end{array}$ & $\begin{array}{l}\text { Ratio } \\
\text { number }\end{array}$ \\
\hline 1 & Loess & 35.00 & 16.7 & - & - & 1601 \\
\hline 2 & Sandstone & 14.62 & 25.2 & 127.2 & 4.2 & 755 \\
\hline 3 & Sandy mudstone & 14.28 & 25.3 & 95.3 & 0.6 & 337 \\
\hline 4 & Fine sandstone & 7.50 & 25.8 & 113.4 & 5.0 & 855 \\
\hline 5 & Sandy mudstone & 23.90 & 25.4 & 76.1 & 1.45 & 437 \\
\hline 6 & Mudstone & 16.31 & 25.0 & 89.7 & 1.36 & 337 \\
\hline 7 & Sandy mudstone & 14.19 & 25.3 & 106.85 & 2.55 & 855 \\
\hline 8 & Sandstone & 19.02 & 24.6 & 94.1 & 4.04 & 328 \\
\hline 9 & Mudstone & 2.82 & 25.4 & 119.5 & 1.56 & 755 \\
\hline 10 & 4\# Coal seam & 4.00 & 13.6 & 40.4 & 0 & 637 \\
\hline 11 & Argillaceous sandstone & 5.43 & 25.2 & 92.5 & 4.35 & 337 \\
\hline 12 & Medium sandstone & 5.84 & 25.0 & 105.2 & 4.06 & 855 \\
\hline 13 & 5\# Coal seam & 4.00 & 13.9 & 45.5 & 0 & 464 \\
\hline 14 & Mudstone & 7.38 & 25.6 & 121.5 & 3.59 & 755 \\
\hline 15 & Sandstone & 7.62 & 25.2 & 95.8 & 4.12 & 337 \\
\hline
\end{tabular}


method), that is, covering the fracture distribution of a certain section of mining overburden rock in the goaf with the r-grid of different scales, and observing the number N(r) of fractures of mining overburden rock located in different scale grids with length greater than or equal to the corresponding grid scale. The fractal law followed by the number of fractures in mining overburden rock and the scale is as follows:

$\mathrm{N}(r)=r^{-D}$

where $D$ is the fractal dimension. The relationship curve between $\ln \mathrm{N}(r)$ and $\ln (r)$ can be obtained by expressing them in the double logarithmic coordinate system. The absolute value of the slope of relationship curve is the fractal dimension $D$ of mining overburden rock. In this physical experiment, when the number of overburden rock fractures under repeated mining is measured by the grid method, it is carried out to scale up the graphics according to the uniform scale and enlarge the range of side length $r$ as far as possible, so as to avoid the scale-free area of self-similar fractal falling out of the effective range and causing large errors, to ensure that the fractal dimensions obtained are more in line with the actual situation of fracture fractals of overburden rock under repeated mining.

In this specific experiment, a section of mining rock mass from 90 to $110 \mathrm{~m}$ away from the open-offcut is selected and covered with the r-grid of $20,10,5$, and 2.5 respectively. The number $\mathrm{N}(r)$ of overburden rock fractures of the repeated mining is counted in the cover area of the caving zone and the fractured zone under different advancing lengths of working face, and the values of $\ln \mathrm{N}(r)$ and $\ln (r)$ are calculated accordingly. The double logarithmic plot is obtained by using the least square method for the best linear fitting, and the fractal dimension $D$ is calculated according to the slope of the fitted straight line.

\section{Results and discussion}

\section{Development and distribution of overburden rock fractures under repeated mining}

For 4\# and 5\# coal seams, the experimental simulation of coal mining was advanced from left to right at a speed of $0.04 \mathrm{~m} / \mathrm{h}$. When the $4 \#$ coal seam is finished, the $5 \#$ coal seam is then mined. The initial excavation (open-offcut) of both starts at 30 $\mathrm{m}$ from the model left, and the final excavation (stop line) of both ends at $270 \mathrm{~m}$ from the model left. The excavation period is in summer. In order to avoid the failure of the model caused by the continuous excavation and the inability to complete the expected test, the excavation was carried out for a total of 10 days from June 26, 2017. That is to say, the mining time was $12 \mathrm{~h}$ a day. The 4\# coal seam was cut at 11:40 on the first day and ended at 20:00 on the fifth day, with a total advance of
$240 \mathrm{~m}$. The $5 \#$ coal seam was cut at 19:30 on the 6 th day and ended at 13:30 on the 10th day, with a total advance of $240 \mathrm{~m}$.

In the process of repeated mining, it appears that with the advance of the working face, the phenomenon of fracture, caving, re-fracture, and re-caving alternately occur in the model. Because the present study mainly focuses on the fracture conditions and fractal characteristics of the rock mass, this paper does not describe the detailed process of overburden collapse and the displacement law of rock mass during the excavation.

On the basis of the observation of the physical similar material simulation experiment, two types of fractures are developed in overburden rock under repeated mining: one is the separation fracture and the other is the vertical fracture fissure. This is the same as the type of fracture development of rock mass of single coal seam in the literature (Liu et al. 2018), but the development of overburden rock fractures under repeated mining is quite different from that of single coal seam.

Figure 2 shows the development of overburden rock fractures corresponding to different advancing lengths of the upper seam (4\# coal seam) working face. It can be seen from Fig. 2 that when the upper seam is mined, the development of overburden rock fractures of the goaf is divided into two stages. The first stage starts from the open-offcut; with the increase of the advancing length of the upper seam working face, the separation fractures of the rock mass of the goaf increases continuously, but the spatial distribution lags behind the advancing length of the working face; the separation fractures in the central rock mass of the goaf are the most developed. In the second stage, with the further increase of the advancing length of the working face, the separation fractures of the rock mass in the central part of the goaf tends to be compacted, which indicates that this stage is the closing stage of the separation fractures of the rock mass, but the separation fractures of the rock mass on both sides still remains, with substantially no major changes. For the vertical fracture fissures, with the increase of the advancing length of the upper seam working face, the vertical fracture fissures continue to develop from the bottom to the top. When the advancing length of the working face is further increased, the vertical fracture fissures will continuously develop forward and upward, but its development also lags behind the advancing length of the upper seam working face. On both sides of the goaf, the formation of vertical fracture fissures is mainly due to the failure of the separated overburden caused by tensile stress. In the central part of the goaf, the formation of vertical fracture fissures is mainly due to the damage of the separated overburden caused by its own gravity. To sum up, based on the observation of the development of overburden rock fractures, in the upper seam mining, with the increase of the advancing length of working face, the fractures of the mining rock 

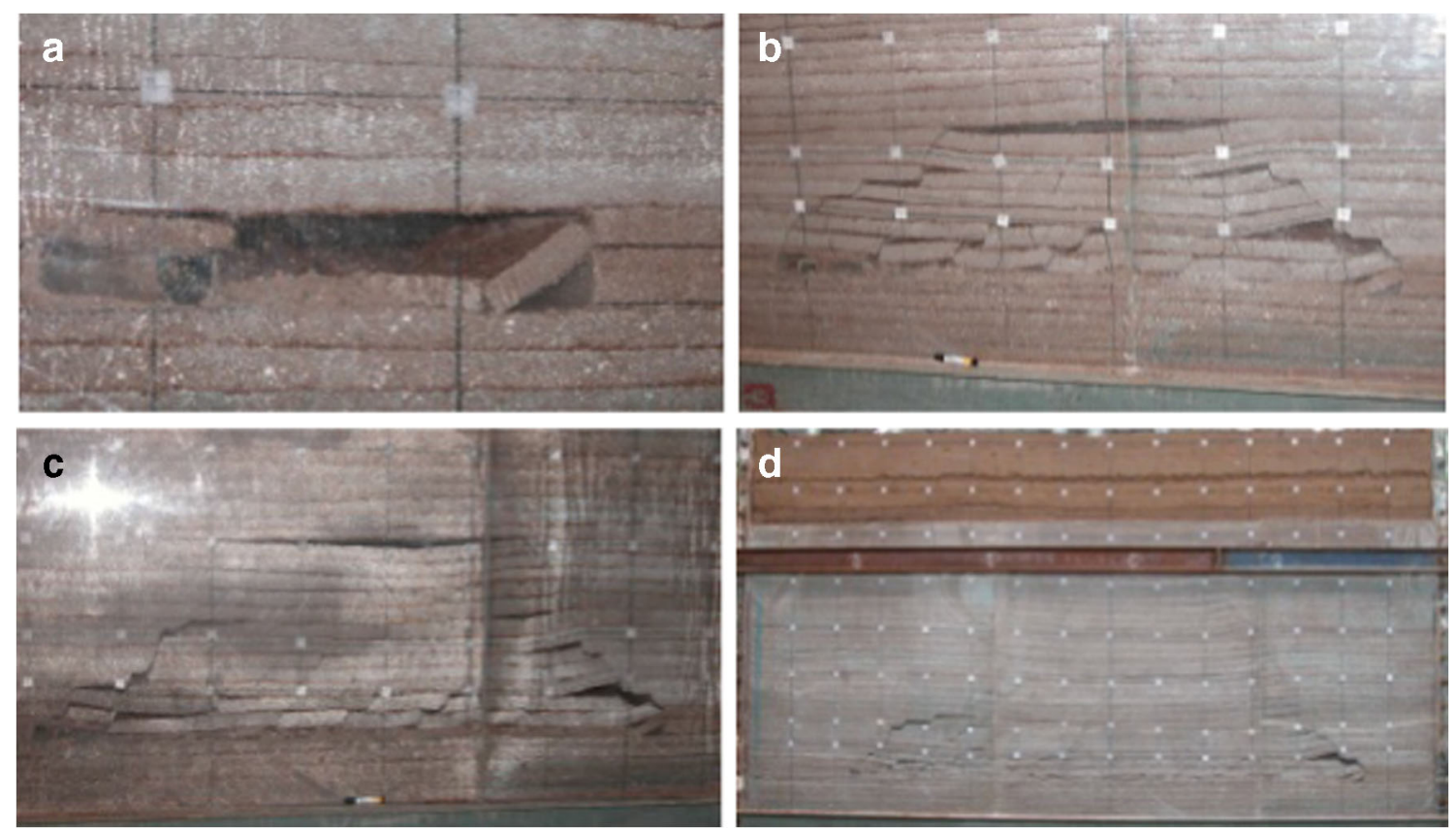

Fig. 2 The schematic diagram of upper mining fractures corresponding to different advancing lengths of working face. $\mathbf{a} \mathrm{L}=38 \mathrm{~m}$. $\mathbf{b} \mathrm{L}=118 \mathrm{~m}$. $\mathbf{c} \mathrm{L}=$ $150 \mathrm{~m}$. d L $=240 \mathrm{~m}$

mass appear successively from the generation to the development, and from the development to the closure.

Figure 3 shows the development of rock mass fractures corresponding to different advancing lengths of the lower seam (5\# coal seam) working face. It can be seen from Fig. 3 that when the lower seam is mined, the integrity of rock mass of the goaf is greatly damaged due to the influence of the upper seam mining. The development of the separation fractures and the vertical fracture fissures of rock mass is no longer developed as that when the upper seam is mined alone, but with the increase of the advancing length of working face of the lower seam,
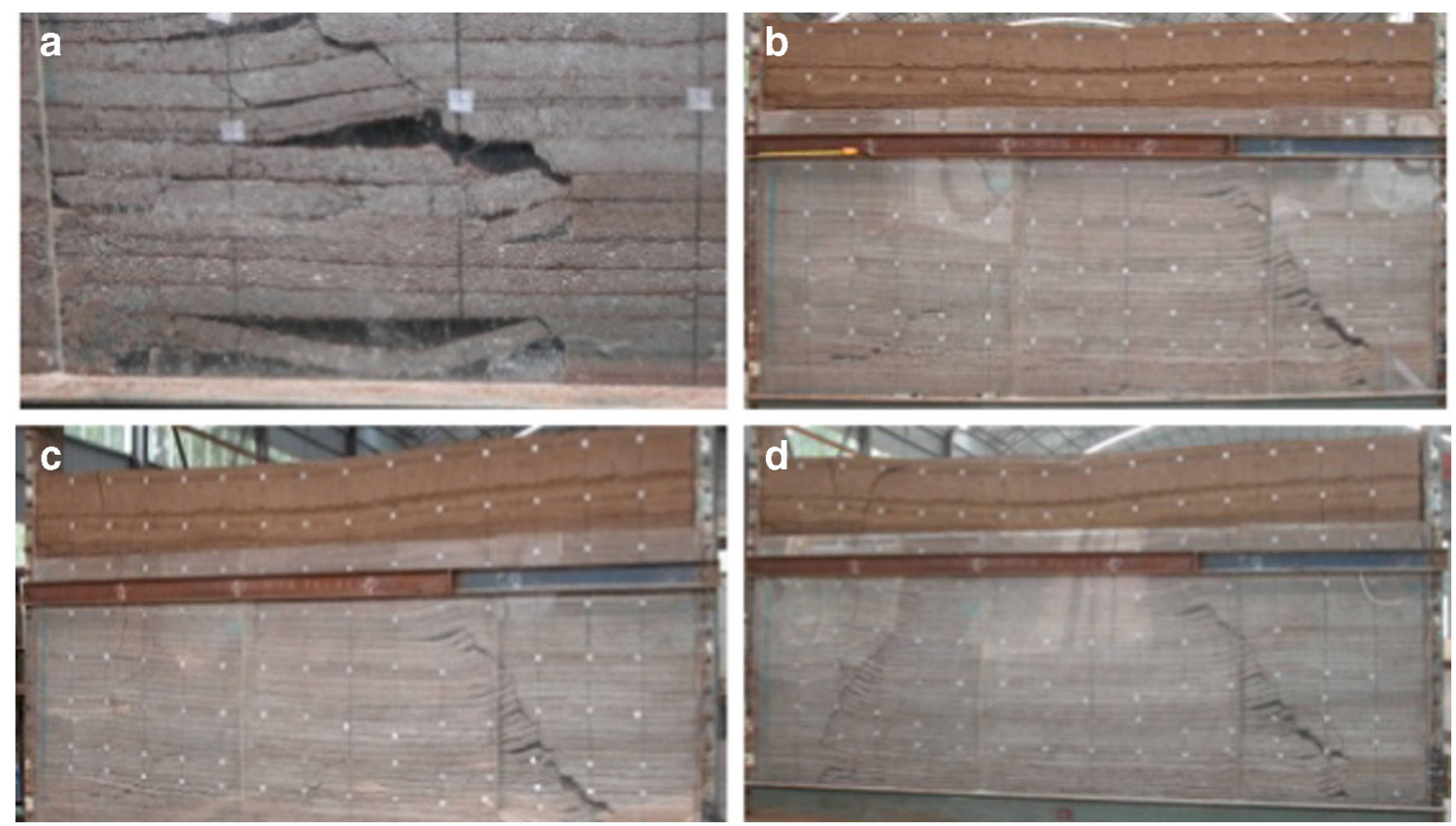

Fig. 3 The schematic diagram of lower mining fractures corresponding to different advancing lengths of working face. $\mathbf{a} \mathrm{L}=38 \mathrm{~m} . \mathbf{b} \mathrm{L}=130 \mathrm{~m} . \mathbf{c} \mathrm{L}=$ $158 \mathrm{~m} . \mathbf{d ~ L}=240 \mathrm{~m}$ 
some large fractures are suddenly formed and/or partial fractures become smaller and then close. There is no regularity of the development of fractures in mining rock mass of the upper seam. However, in the area where the upper seam mining has no effects, the fracture development of the lower seam mining is still the same as that of the upper seam mining. Under the influence of repeated mining, when the lower seam mining is over and the rock mass movement is basically stable, the fractures developed in the rock mass of the goaf are obviously retained in general. The number of overburden rock fractures on both sides of the goaf is relatively large, while in the central part, it is relatively small and overburden rock fractures in most areas are basically closed.

In summary, under the condition of repeated mining, the development of fractures in mining overburden rock has both similarities and differences as single coal seam. The development of overburden rock fractures under repeated mining is more complex than that of single coal seam.

\section{Fractal characteristics of overburden rock fractures under repeated mining}

In order to further study the fractal characteristics of overburden rock fractures under repeated mining, this paper takes a section of mining rock mass from 90 to $110 \mathrm{~m}$ away from the open-offcut as an example, to calculate fractal dimension of overburden rock fractures under repeated mining in the caving zone and the fractured zone under different advancing lengths of working face of the lower seam (5\# coal seam). In the specific calculation, firstly, the mining rock mass is covered with the r-grid of $20,10,5$, and 2.5 , respectively; secondly, the number $\mathrm{N}(r)$ of overburden rock fractures under repeated mining is counted, and the values of $\ln \mathrm{N}(r)$ and $\ln (r)$ are calculated accordingly; lastly, the corresponding fractal dimension of overburden rock fractures under repeated mining is obtained by using the least square method for the best linear fitting. The calculation results of fractal dimension of overburden rock fractures of the caving zone and the fractured zone of repeated mining goaf are shown in Table 3.

It can be seen from Table 3 that the number of overburden rock fractures in the caving zone and fractured zone is different, and the corresponding fractal dimension of overburden rock fractures is also different. At the same scale $r$, the development of overburden rock fractures in the caving zone is more than that in the fractured zone, further indicating that the deformation and failure degree of rock mass in the caving zone is more severe than that in the fractured zone under the impacts of repeated mining.

The variation curves of fractal dimension of overburden rock fractures in the caving zone and the fractured zone with advancing lengths of the lower seam working face are shown in Fig. 4. According to Fig. 4, it can be concluded that in the study area of mining rock mass with a length of $20 \mathrm{~m}$, the fractal dimension of overburden rock fractures under repeated mining presents the following basic laws: (1) under the same advancing length of working face in the lower coal seam, the fractal dimension of the caving zone is larger than that of the fractured zone in the goaf, and the fractal dimension of the caving zone is basically 1.0 to 1.2 times of the fractured zone; (2) with the increase of the advancing length of the lower coal seam, the variation trend of fractal dimension of overburden rock fractures under repeated mining appears from small to large and then to small and stable; (3) when the repeated mining is over and the overburden rock movement is basically stable, the fractal dimension of overburden rock fractures in the caving zone and the fractured zone of the goaf is 1.0663 and 0.9995 , respectively; the former is 1.067 times that of the latter.

\section{Discussion}

According to the calculation results of fractal dimension of overburden rock fractures under repeated mining mentioned above, as the different deformation and failure during the lower seam mining, the fractal dimensions of overburden rock fractures in the caving zone and the fractured zone are also different. The fractal dimensions in the caving zone are always greater than that of the fractured zone. It indicates that under the condition of repeated mining, the development of fractures of the caving zone is higher than that of the fractured zone due to the close proximity of the mining coal seam. This is in contrast to the fractal dimension of the caving zone and the fractured zone under the condition of single coal seam mining described in the literature ( $\mathrm{Li}$ et al. 2010). In addition, the fractal dimension of overburden rock fractures under repeated mining appears from small to large and then to small and stable with the increase of the advancing length of the lower seam. However, the results of the literature (Zhang et al. 2004; Li et al. 2010; Zhou et al. 2011) indicate that under the mining conditions of single coal seam, with the increase of the advancing length of the mining working face, the fractal dimension of mining rock mass in goaf has an increasing trend. These fully demonstrate that the variation of fractal dimension of overburden rock fractures under repeated mining is very different from that of single seam mining. This is mainly due to that under the impact of the upper seam mining (4\# coal seam), the impact of the lower seam mining (5\# coal seam) is superimposed. That is, due to the impact of repeated mining, the integrity of the overlying rock mass of the goaf is damaged. When the lower seam mining is over and the rock strata movement is basically stable, the number of overburden rock fractures in the caving zone and the fractured zone of 
Table 3 Fractal dimension of overburden rock fractures under repeated mining

\begin{tabular}{|c|c|c|c|c|c|}
\hline \multirow[t]{2}{*}{ Advancing length } & \multirow[t]{2}{*}{ Scale $r$} & \multicolumn{2}{|c|}{ Caving zone } & \multicolumn{2}{|c|}{ Fractured zone } \\
\hline & & $\mathrm{N}(r)$ & Fractal dimension $D$ & $\mathrm{~N}(r)$ & Fractal dimension $D$ \\
\hline \multirow[t]{4}{*}{$\mathrm{L}=102 \mathrm{~m}$} & 20 & 0 & \multirow[t]{4}{*}{1.0844} & 0 & \multirow[t]{4}{*}{1.0002} \\
\hline & 10 & 2 & & 0 & \\
\hline & 5 & 4 & & 2 & \\
\hline & 2.5 & 9 & & 4 & \\
\hline \multirow[t]{4}{*}{$\mathrm{L}=118 \mathrm{~m}$} & 20 & 3 & \multirow[t]{4}{*}{1.2149} & 0 & \multirow[t]{4}{*}{0.9995} \\
\hline & 10 & 7 & & 1 & \\
\hline & 5 & 17 & & 2 & \\
\hline & 2.5 & 37 & & 4 & \\
\hline \multirow[t]{4}{*}{$\mathrm{L}=126 \mathrm{~m}$} & 20 & 5 & \multirow[t]{4}{*}{1.2173} & 2 & \multirow[t]{4}{*}{1.0740} \\
\hline & 10 & 12 & & 4 & \\
\hline & 5 & 25 & & 8 & \\
\hline & 2.5 & 53 & & 19 & \\
\hline \multirow[t]{4}{*}{$\mathrm{L}=152 \mathrm{~m}$} & 20 & 4 & \multirow[t]{4}{*}{1.2235} & 3 & \multirow[t]{4}{*}{1.1203} \\
\hline & 10 & 9 & & 7 & \\
\hline & 5 & 21 & & 15 & \\
\hline & 2.5 & 51 & & 31 & \\
\hline \multirow[t]{4}{*}{$\mathrm{L}=240 \mathrm{~m}$} & 20 & 3 & \multirow[t]{4}{*}{1.0663} & 0 & \multirow[t]{4}{*}{0.9995} \\
\hline & 10 & 6 & & 1 & \\
\hline & 5 & 12 & & 2 & \\
\hline & 2.5 & 28 & & 4 & \\
\hline
\end{tabular}

repeated mining goaf is decreased by the influence of compaction and closure, and finally, the fractal dimension of the mining rock mass is also decreased.

In addition, according to the statistics of the displacement monitoring data of the model rock mass, after repeated mining, the maximum subsidence values of the caving zone, the fractured zone and the bending zone are $7.56 \mathrm{~m}, 7.01 \mathrm{~m}$, and $6.99 \mathrm{~m}$, respectively. The average subsidence value is

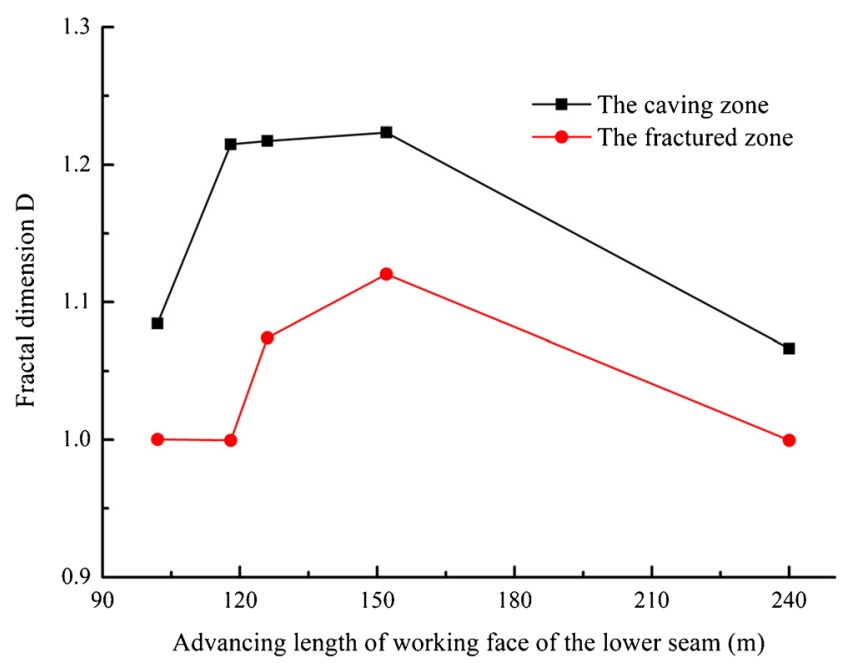

Fig. 4 The variation curve of fractal dimension of overburden rock fractures under repeated mining calculated as $7.18 \mathrm{~m}$. In fact, the maximum in situ surface subsidence of the working face measured by the relevant monitoring department of the coal mine is $7.59 \mathrm{~m}$. The difference between the simulated value and the measured value is 0.41 $\mathrm{m}$, and the relative error between the two is $5.71 \%$, which is far less than $10 \%$. This shows that the model of the similar simulation experiment is effective and reliable. It can further show that the fractal dimension obtained from model experiment is credible and can reflect the actual situation of the prototype well.

Thus, it can be seen that for the personnel who carry out the stability evaluation of the foundation of the goaf under the expressway and the design of the filling and grouting of the goaf, to ensure the safety of the expressway, it is necessary to carry out relevant research based on the study of fracture development and fractal characteristics of overburden rock under repeated mining, which should be given high attention. Otherwise, it will cause issues such as unreasonable evaluation of foundation stability and/or waste of resources due to over-conservation of grouting design.

\section{Conclusions}

The fracture development and fractal characteristics of overburden rock under repeated mining are studied using 
physical similar material simulation experiment and the fractal geometry theory, and the key findings from this paper can be summarized as follows.

(1) During the advancement of mining working face, two types of fractures are developed in overburden rock of repeated mining goaf: one is the separation fracture and the other is the vertical fracture fissure. This is the same as the type of the development of rock mass fractures in single coal seam.

(2) Under the impact of repeated mining, after the mining of the lower coal seam, the fractures developed in the overburden rock of the goaf are obviously retained in general. The number of overburden rock fractures on both sides of the goaf is relatively large, while in the central part it is relatively small and the overburden rock fractures in most areas are basically closed. The development of overburden rock fractures under repeated mining is more complicated than that of single coal seam.

(3) Under the same advancing length of working face in the lower coal seam, the fractal dimension of the caving zone is larger than that of the fractured zone in the goaf, and the fractal dimension of the caving zone is basically 1.0 to 1.2 times of the fractured zone.

(4) With the increase of the advancing length of working face in the lower coal seam, the variation trend of fractal dimension of overburden rock fractures under repeated mining appears from small to large and then to small and stable. This is different from the variation trend of fractal dimension of single coal seam.

(5) When the repeated mining is over and the overburden rock movement is basically stable, the fractal dimension of overburden rock fractures in the caving zone and the fractured zone in the goaf is 1.0663 and 0.9995 , respectively; the ratio of the two fractal dimensions is 1.067:1.

(6) To ensure the safety of the expressway, it is necessary to carry out relevant research based on the study of fracture development and fractal characteristics of overburden rock under repeated mining.

(7) The results provide a theoretical basis for the stability evaluation of the foundation and the design of the grouting of repeated mining goaf under the expressways in Shanxi region and similar areas.

Acknowledgements The authors gratefully appreciate all the valuable comments and suggestions from the anonymous reviewers and editors, which helped to improve the quality of the manuscript greatly.

Author contribution The work was coordinated by the corresponding author Zhixiang Zhang and Yongbo Zhang. Qiang Zheng, Zhaoliang Wang, Liangliang Guo performed the experiment. This paper was mainly written by Zhixiang Zhang and Yongbo Zhang. Yongxin Xu revised the manuscript.
Funding This study was supported in part by the National Natural Science Foundation of China (No. 41572221) and the National Natural Science Foundation of China (No. 41807195).

\section{References}

Babadagli T (2001) Fractal analysis of 2-D fracture networks of geothermal reservoirs in south-western Turkey. J Volcanol Geotherm Res 112(1):83-103

Cheng X, Zhao G, Li Y, Meng X, Dong C, Liu Z (2018) Researches of fracture evolution induced by soft rock protective seam mining and an omni-directional stereo pressure-relief gas extraction technical system: a case study. Arab J Geosci 11:326. https://doi.org/10. 1007/s12517-018-3666-4

Fan G, Zhang D, Chen M, Zhang S (2019) Dissipative structure feature of mining fractured overburden system and threshold effect of catastrophic instability. J Min Saf Eng 36(6):1093-1101 (In Chinese)

Feng J, Liu X, Yu Z (2017) Numerical simulation study on the mininginduced fracture evolution of steep coal seam. J China Coal Soc 42: 1971-1978 (In Chinese)

Li Z, Ding X, Cheng Z (2010) Research on fractal characteristics of overlying strata crack evolution in coal seam with thin bedrock. J Min Saf Eng 27:576-580 (In Chinese)

Li H, Wang W, Qi Q, Zhang L (2014) Study on fissure development rule of overlying strata influenced by mining based on fractal theory. J China Coal Soc 39(6):1023-1030 (In Chinese)

Li D, Zhou H, Xue D, Yi H, Gao H (2015) Relationship between percolation and fractal properties of mining-induced crack network in coal and rock masses. Rock Soil Mech 36:1135-1140 (In Chinese)

Li S, Ding Y, An Z, Li H, Wei X (2016) Experimental research on the shape and dynamic evolution of repeated mining-induced fractures in short-distance coal seams. J Min Saf Eng 33:904-910 (In Chinese)

Liang T, Liu X, Wang S (2019) Fractal study on the crack network evolution and permeability change in mining rock mass. J China Coal Soc 44(12):3729-3739 (In Chinese)

Liu J, Li J, Geng Q, Zheng X (2018) In-situ measurement and simulation of regional mining-induced fracture evolution. Journal of Liaoning Technical University (Natural Science) 37(1):49-55 (In Chinese)

Lu Y, Wang L (2015) Numerical simulation of mining-induced fracture evolution and water flow in coal seam floor above a confined aquifer. Comput Geotech 67:157-171

Mandelbrot BB (1983) The fractal geometry of nature. W. H. Freeman \& Co., New York, 468p

Poulsen BA, Adhikary D, Guo H (2018) Simulating mining-induced strata permeability changes. Eng Geol 237:208-216

Sofianos AI (1996) Analysis and design of an underground hard rock Voussoir beam roof. Int J Rock Mech Min Sci Geomech Abstr 33: 153-166

Song B, Chen L, Zhang F, Chen L, Li H (2017) Study on the evolution law of the fracture influenced by mining based on fractal theory. Geotechnical Investigation \& Surveying (1):1-6 (In Chinese)

Wang J, Wang Z (2018) Propagating mechanism of top-coal fracture in longwall top-coal caving mining. J China Coal Soc 43(9):23762388 (In Chinese)

Wang G, Yu G, Yu Y, Lu S, Kang Y (2012) Study on cracks fractal evolution laws of mining rock mass. J Min Saf Eng 29:859-863 (In Chinese)

Wang C, Zhang Q, Li J, Liu W (2017) Similar simulation of overlying strata fracture development under repeated mining in shallow. Coal Mining Technol 22(6):78-81 (In Chinese)

Wang S, Zhao J, Zhang L (2019) Numerical simulation of mininginduced fracture development of roof of Shennanwa coal mine. Safety in Coal Mines 50(10):231-234 (In Chinese) 
Xu G, Li H, Guan J (2018) Laws of overburden strata rupture and fissure evolution during mining under water body. Safety in Coal Mines 49(4):42-45 (In Chinese)

Zhang J (2017) Mining-induced stress characteristics and fracture evolution law of over one kilometer deep Pingdingshan coal mine. J China Univ Min Technol 46(5):1041-1049 (In Chinese)

Zhang Y, Liu X (2004) Testing study on fractal characteristics of cracks in mining rock masses. Ground Pressure and Strata Control 23:94 95 (In Chinese)

Zhang Y, Jin Z, Liu X (2004) Testing study on fractal correlation law of cracks in mined rock masses. Chin J Rock Mech Eng 23:3426-3429 (In Chinese)

Zhang Y, Zhang B, Zhang C, Zhao J, Liu J, Zhang S (2013) Study of the dynamic evolution rules and distribution pattern of mining-induced fractures of thick coal seam. J China Univ Min Technol 42:935-940 (In Chinese)

Zhang R, Ai T, Zhou H, Ju Y, Zhang Z (2015a) Fractal and volume characteristics of 3D mining-induced fractures under typical mining layouts. Environ Earth Sci 73:6069-6080
Zhang Y, Zhang C, Zhao F (2015b) Dynamic evolution rules of mininginduced fractures in different floor area of short-distance coal seams. J China Coal Soc 40(4):786-792 (In Chinese)

Zhang Y, Cao S, Guo S, Wan T, Wang J (2018a) Mechanisms of the development of water-conducting fracture zone in overlying strata during shortwall block backfill mining: a case study in Northwestern China. Environ Earth Sci 77:543

Zhang Y, Xu Y, Wang K, Chen P, Wang X, Zheng Q, Zhang Z (2018b) The fracturing characteristics of rock mass of coal mining and its effect on overlying unconsolidated aquifer in Shanxi, China. Arab J Geosci 11:666. https://doi.org/10.1007/s12517-018-4034-0

Zhou S, Lin B (1999) Theory of gas occurrence and flow in coal seam. Beijing: the Press of Coal Industry (In Chinese)

Zhou H, Zhang T, Xue D, Xue J (2011) Evolution of mining-induced crack network in overburden strata of longwall face. J China Coal Soc 36:1957-1962 (In Chinese)

Zhu W (2019) Developing rule and engineering application of mining fracture under thick unconsolidated layers and thin bedrock. Metal Mine 10:126-132 (In Chinese) 